Research Paper

\title{
VEGF -634C/G Genotype is Predictive of Long-term Survival after Treatment with a Definitive 5-Fluorou- racil/cisplatin-based Chemoradiotherapy in Japanese Patients with Esophageal Squamous Cell Carcinoma
}

\author{
Takao Tamura 1,2, Akiko Kuwahara 2,3, Motohiro Yamamori 2,3, Kohshi Nishiguchi 2,4, Tsutomu Nakamura \\ 2, Tatsuya Okuno ${ }^{2}$, Ikuya Miki ${ }^{2}$, Yuki Manabe ${ }^{5}$ and Toshiyuki Sakaeda 2,5 \\ 1. Department of Medical Oncology, Nara Hospital, Kinki University Faculty of Medicine, Nara 630-0293, Japan. \\ 2. Kobe University Graduate School of Medicine, Kobe 650-0017, Japan. \\ 3. School of Pharmacy and Pharmaceutical Sciences, Mukogawa Women's University, Nishinomiya 663-8179, Japan. \\ 4. Department of Clinical Pharmacy, Kyoto Pharmaceutical University, Kyoto 607-8414, Japan. \\ 5. Graduate School of Pharmaceutical Sciences, Kyoto University, Kyoto 606-8501, Japan.
}

$\square$ Corresponding author: Toshiyuki Sakaeda, Ph.D., Center for Integrative Education in Pharmacy and Pharmaceutical Sciences, Graduate School of Pharmaceutical Sciences, Kyoto University, Kyoto 606-8501, Japan, Tel: +81-75-753-9560, Fax: +81-75-753-9253, e-mail: sakaedat@pharm.kyoto-u.ac.jp.

(C) Ivyspring International Publisher. This is an open-access article distributed under the terms of the Creative Commons License (http://creativecommons.org/ licenses/by-nc-nd/3.0/). Reproduction is permitted for personal, noncommercial use, provided that the article is in whole, unmodified, and properly cited.

Received: 2012.07.23; Accepted: 2012.10.15; Published: 2012.11.0I

\begin{abstract}
Background: Reports have been accumulating that genetic properties are predictive of clinical response after and/or toxicity during cancer chemotherapy, but little information is available concerning effects on long-term survival. In this study, 49 Japanese patients with esophageal squamous cell carcinoma (ESCC) were followed up for 5 years after treatment with a definitive 5 -fluorouracil (5-FU)/cisplatin (CDDP)-based chemoradiotherapy (CRT), and the effects of genotypes of vascular endothelial growth factor (VEGF) were retrospectively revaluated in terms of prediction of long-term survival.

Methods: A course consisted of the continuous infusion of $5-\mathrm{FU}$ at $400 \mathrm{mg} / \mathrm{m}^{2} /$ day for days $\mathrm{I}-5$ and $8-12$, the infusion of CDDP at $40 \mathrm{mg} / \mathrm{m}^{2} /$ day on days I and 8 , and radiation at $2 \mathrm{~Gy} /$ day on days I to 5,8 to 12 , and 15 to 19 , with a second course repeated after a 2-week interval. The VEGF genotypes -I498T/C, -II54G/A, -634C/G, -7C/T, 936C/T, and I6/2G/A were evaluated.

Results: The complete response (CR) rate was $46.9 \%$ (23/49). The 5 -year survival rate was $42.9 \%$ (2I/49). There were 7 patients with a CR, but survival of less than 5 years. They died from myocardial infarction $(\mathrm{N}=\mathrm{I})$, sudden cardiac death after suffering from heart failure $(N=I)$, acute myeloid leukemia that developed from myelodysplastic syndromes $(N=I)$, factors not specified $(N=2)$, oropharynx cancer $(N=I)$, and tongue cancer $(N=I)$. VEGF $-634 \mathrm{C} / \mathrm{G}$ had no effect on clinical response, but long-term survival depended on the genotype $(p=0.033$, Fisher's; $p=0.038$, Cochran-Armitage; $p=0.079$, Log-rank). The genotype frequency of 7 patients with a CR, but survival of less than 5 years was different from that for the other 42 patients $(p=0.032$, Fisher's). None of the other 5 genotypes evaluated affected either clinical response or survival.

Conclusions: VEGF $-634 \mathrm{C} / \mathrm{G}$ is possibly predictive of long-term survival after treatment with a definitive 5-FU/CDDP-based CRT. Further clinical studies with a larger number of cases are needed to clarify the effects of this genotype.
\end{abstract}

Key words: esophageal squamous cell carcinoma, chemoradiotherapy, late toxicity, prognosis, vascular endothelial growth factor. 


\section{Background}

A clinical report published in 1999, the RTOG (Radiation Therapy Oncology Group) 85-01 trial involving 134 patients with T1-3, N0-1, and M0 esophageal cancer, was of great interest in terms of clinical outcome because it demonstrated a 5-year survival rate of $26 \%$ [1-4]. This treatment consists of a 96-hr-infusion of 5-fluorouracil (5-FU) at a daily dose of $1,000 \mathrm{mg} / \mathrm{m}^{2} /$ day in weeks $1,5,8$, and 11 , infusion of cisplatin (CDDP) at $75 \mathrm{mg} / \mathrm{m}^{2} /$ day on the first day of weeks $1,5,8$, and 11 , and concurrent radiation at 50 Gy in 25 fractions over 5 weeks. Immediately thereafter, another version of chemoradiotherapy (CRT) was proposed for advanced esophageal squamous cell carcinoma (ESCC), which consists of a 120-hr-infusion of $5-\mathrm{FU}$ at $400 \mathrm{mg} / \mathrm{m}^{2} /$ day in weeks $1,2,6$, and 7 , infusion of CDDP at $40 \mathrm{mg} / \mathrm{m}^{2} /$ day on the first day of weeks $1,2,6$, and 7 , and concurrent radiation at $60 \mathrm{~Gy}$ in 30 fractions over 8 weeks $[5,6]$. Two independent clinical investigations have shown curative potential using this regimen for unresectable ESCC with T4 or M1a $[5,6]$, and a long-term evaluation of efficacy and toxicity with 139 patients resulted in a complete response (CR) rate of $56 \%$, along with a 5-year survival rate of $29 \%$ [7-9]. Of note, however, treatment-related late toxicities were severe, and life-threatening cardiopulmonary toxicities might have occurred, including pericarditis, heart failure, myocardial infarction/cardiac ischemia, pleural effusion, and radiation pneumonitis [8-10]. The incidence of mortality due to cardiopulmonary late toxicities was relatively high for patients with a CR $[8,9]$; however, it was low in two large randomized trials, in which the benefits of combining CRT with surgical treatment were evaluated $[11,12]$. Currently, a definitive 5-FU/CDDP-based CRT is recognized as one of the most promising treatments for esophageal cancer, but given the extensive inter-individual variation in clinical outcome, future improvements will likely require the dose-modification of these regimens, incorporation of a novel anticancer drug, pharmacokinetically guided administration of 5-FU or CDDP, and identification of responders via patient genetic profiling [13].

A series of studies has been performed to find a marker predictive of clinical response 1 month after or severe acute toxicities during treatment with a definitive 5-FU/CDDP-based CRT in Japanese patients with ESCC [14-19]. The genotypes of vascular endothelial growth factor (VEGF), an endothelial cell-specific mitogen, were evaluated [16], since clinical reports suggested that their genetic variations have the potential to influence the expression of VEGF, and thereby the growth of tumors, metastatic spread, and response to treatment [20-23]; however, they failed to predict the response [16]. Obviously, the final goal of cancer chemotherapy is an improvement in long-term survival, not a short-term clinical response, so parameters predicting prognosis have been absolutely imperative. In this study, patients with ESCC were followed up for 5 years after treatment with a definitive 5-FU/CDDP-based CRT, and the effects of VEGF genotypes were retrospectively re-evaluated in terms of prediction of long-term survival.

\section{Methods}

\section{Patients and study protocol}

Forty-nine ESCC patients treated with a definitive 5-FU/CDDP-based CRT at Kobe University Hospital, Japan, from October, 2003 to June, 2006 were followed up for 5 years. Survival time was defined as the time from treatment initiation to death from any cause or to the last date of confirmation of survival. Survival data were updated on June 25, 2011. The inclusion criteria for treatment basically included; 1 ) clinical stage $\mathrm{T} 1$ to $\mathrm{T} 4, \mathrm{~N} 0$ or $\mathrm{N} 1$, and $\mathrm{M} 0$ or M1 according to the International Union Against Cancer tumor-node-metastasis (TNM) classification; 2) age less than 85 years; 3 ) an Eastern Cooperative Oncology Group performance status of 0 to $2 ; 4$ ) adequate bone marrow, renal, and hepatic function; 5) no prior chemotherapy; 6) no severe medical complications; and 7) no other active malignancies (except early cancer). The tumors were histologically confirmed to be primary, and no patients with recurrence were included in this study.

A course consisted of the continuous infusion of 5 -FU at $400 \mathrm{mg} / \mathrm{m}^{2} /$ day for days $1-5$ and $8-12$, the infusion of CDDP at $40 \mathrm{mg} / \mathrm{m}^{2} /$ day on days 1 and 8 , and radiation at $2 \mathrm{~Gy} /$ day on days 1 to 5,8 to 12 , and 15 to 19 , with a second course repeated after a 2-week interval $[5,6]$. If disease progression/recurrence was observed, either salvage surgery, endoscopic treatment, or another regimen of chemotherapy was scheduled. The VEGF genotypes -1498T/C (known as $-460 \mathrm{~T} / \mathrm{C}, \mathrm{rs} 833061)$ and $-1154 \mathrm{G} / \mathrm{A}$ (rs1570360) in the promoter region, $-634 \mathrm{C} / \mathrm{G}$ (known as $405 \mathrm{C} / \mathrm{G}$, rs2010963) and -7C/T (rs25648) in the $5^{\prime}$ untranslated region (UTR), and 936C/T (rs3025039) and 1612G/A (rs10434) in the 3'UTR, were evaluated using peripheral blood and the TaqMan ${ }^{\mathrm{R}}$ MGB probe-based polymerase chain reaction and confirmed by direct sequencing. This study was conducted with the authorization of the institutional review board and followed the medical research council guidelines of Kobe University. Written informed consent was obtained from all participants prior to genotyping. The associ- 
ations with clinical response and severe acute toxicities were already reported [16], and their effects on long-term survival were evaluated in this study. It should be noted that the patients in this study were almost the same as those in the previous report [16].

\section{Clinical response}

The clinical response was evaluated as reported previously [5-9]. Briefly, a CR was defined as the complete disappearance of all measurable and assessable disease at the first evaluation, which was performed 1 month after the completion of CRT to determine whether the disease had progressed. The clinical response was evaluated by endoscopy and chest and abdominal computed tomography (CT) scans in each course. A CR at the primary site was given by endoscopic examination when all of the following criteria were satisfied on observation of the entire esophagus: 1) disappearance of the tumor lesion; 2) disappearance of ulceration (slough); and 3) absence of cancer cells in biopsy specimens. If small nodes of $1 \mathrm{~cm}$ or less were detected on CT scans, the recovery was defined as an "uncertain CR" after confirmation of no progression for at least 3 months. An "uncertain CR" was included as a CR when calculating the $C R$ rate. When these criteria were not satisfied, a non-CR was assigned. The existence of erosion, a granular protruded lesion, an ulcer scar, and 1.2 $\mathrm{w} / \mathrm{v} \%$ iodine/glycerin-voiding lesions did not prevent an evaluation of CR. The evaluations were performed every month for the first 3 months, and when the criteria for $C R$ were not satisfied at 3 months, the result was changed to non-CR. Follow-up evaluations were performed thereafter every 3 months for 3 years by endoscopy and CT scan. After 3 years, patients were seen every 6 months. During the follow-up period, a routine course of physical examinations and clinical laboratory tests was performed to check the patient's health.

\section{Data analysis and statistics}

All values reported are the mean \pm standard deviation (SD) without any explanatory notes. The Fisher's exact test, Cochran-Armitage test, Recessive and Dominant test and Log-rank test were used for evaluation of the effects of genotypes on long-term survival. $\mathrm{P}$ values of less than 0.05 (two tailed) were considered to be significant.

\section{Results}

Demographic and clinicopathologic characteristics of 49 Japanese ESCC patients are summarized in Table 1. The average age was $64.5 \pm 7.4$ years (range: 48-78) and the average weight was $56.1 \pm 9.6 \mathrm{~kg}$ (range:
33-79). The ratio of $\mathrm{T} 1 / \mathrm{T} 2 / \mathrm{T} 3 / \mathrm{T} 4$ was $16 / 6 / 15 / 12$, that of N0/N1 was $22 / 27$, and that of M0/M1 was $41 / 8$, resulting in a stage $\mathrm{I} / \mathrm{II} / \mathrm{III} / \mathrm{IV}$ ratio of $12 / 10 / 19 / 8$. The CR rate and 5-year survival rate were $46.9 \%(23 / 49)$ and $42.9 \%(21 / 49)$, respectively. The 5-year survival rate was $69.6 \%(16 / 23)$ for the patients with a CR, but only $19.2 \%(5 / 26)$ for those with a non-CR, and survival depended on clinical response, i.e., $C R$ or non- $C R \quad(P=0.0005$, Fisher's; $\mathrm{p}=0.001$, Log-rank).

The frequencies of VEGF genotypes in the 49 patients are listed in Table 2. Among the 6 genotypes evaluated, only $-634 \mathrm{C} / \mathrm{G}$ affected survival $(\mathrm{p}=0.033$, Fisher's; $\mathrm{p}=0.038$, Cochran-Armitage). Figure 1 shows the association of VEGF -634C/G with survival. The median overall survival time $( \pm$ SE) was $29.5 \pm 22.3$ months for all patients, and more than 60 months, more than 60 months, and 13.0 \pm 9.0 months for the patients with $\mathrm{CC}^{-634}, \mathrm{CG}^{-634}$, and $\mathrm{GG}^{-634}$, respectively, but the genotype did not have enough power to predict survival ( $\mathrm{P}=0.079$, Log-rank). There were 7 patients with a $C R$, but a survival of less than 5 years. They died from myocardial infarction $(\mathrm{N}=1)$, sudden cardiac death after suffering from heart failure $(\mathrm{N}=1)$, acute myeloid leukemia that developed from myelodysplastic syndromes $(\mathrm{N}=1)$, factors not specified $(\mathrm{N}=2)$, oropharynx cancer $(\mathrm{N}=1)$, and tongue cancer $(\mathrm{N}=1)$. Their genotype frequency is listed in Table 3. Their genotype frequency was different from that for the other 42 patients ( $p=0.032$, Fisher's).

Table I. Demographic and clinicopathologic characteristics of 49 Japanese patients with esophageal squamous cell carcinoma.

\begin{tabular}{ll}
\hline Age, yr & $64.5 \pm 7.4(48-78)$ \\
Height, cm & $163.5 \pm 6.6(150-180)$ \\
Weight, kg & $56.1 \pm 9.6(33-79)$ \\
Male/Female & $46 / 3$ \\
Performance status, 0/1/2/unknown & $24 / 20 / 4 / 1$ \\
Differentiation, & $7 / 28 / 8 / 6$ \\
well/moderate/ poor/unknown & \\
T1/T2/T3/T4 & $16 / 6 / 15 / 12$ \\
N0/N1 & $22 / 27$ \\
M0/M1 & $41 / 8$ \\
Stage I/II/III/IV & $12 / 10 / 19 / 8$ \\
\hline
\end{tabular}

The values are the mean $\pm \mathrm{SD}$, with the range in parentheses. 
Table 2. VEGF genotypes and survival after treatment with a definitive 5-fluorouracil/cisplatin-based chemoradiotherapy in 49 Japanese patients with esophageal squamous cell carcinoma.

\begin{tabular}{llllll}
\hline & & total & $\begin{array}{l}5 \text { years } \\
\text { or more }\end{array}$ & $\begin{array}{l}\text { less than } 5 \\
\text { years }\end{array}$ & P a) \\
\hline$-1498 \mathrm{~T} / \mathrm{C}$ & TT & 22 & 9 & 13 & $0.280(0.825)$ \\
& TC & 24 & 12 & 12 & \\
& CC & 3 & 0 & 3 & $0.655(0.573)$ \\
$-1154 \mathrm{G} / \mathrm{A}$ & GG & 36 & 16 & 20 & \\
& GA & 11 & 5 & 6 & $0.033(0.042)$ \\
& AA & 2 & 0 & 2 & \\
$-634 \mathrm{C} / \mathrm{G}$ & CC & 9 & 5 & 4 & $0.616(0.782)$ \\
& CG & 26 & 14 & 12 & \\
& GG & 14 & 2 & 12 & $1.000(0.614)$ \\
$-7 \mathrm{C} / \mathrm{T}$ & CC & 35 & 14 & 21 & \\
& CT & 13 & 7 & 6 & \\
& TT & 1 & 0 & 1 & $0.438(0.460)$ \\
936C/T & CC & 31 & 14 & 17 & \\
& CT & 17 & 7 & 10 & \\
& TT & 1 & 0 & 1 & \\
$1612 \mathrm{G} / \mathrm{A}$ & GG & 41 & 19 & 22 & 6 \\
& GA & 8 & 2 & 6 & \\
& AA & 0 & 0 & 0 & \\
\hline
\end{tabular}

a) more than 5 years vs. less than 5 years; $P$ values by Fisher's exact test for genotype frequencies with allele frequencies in parentheses.

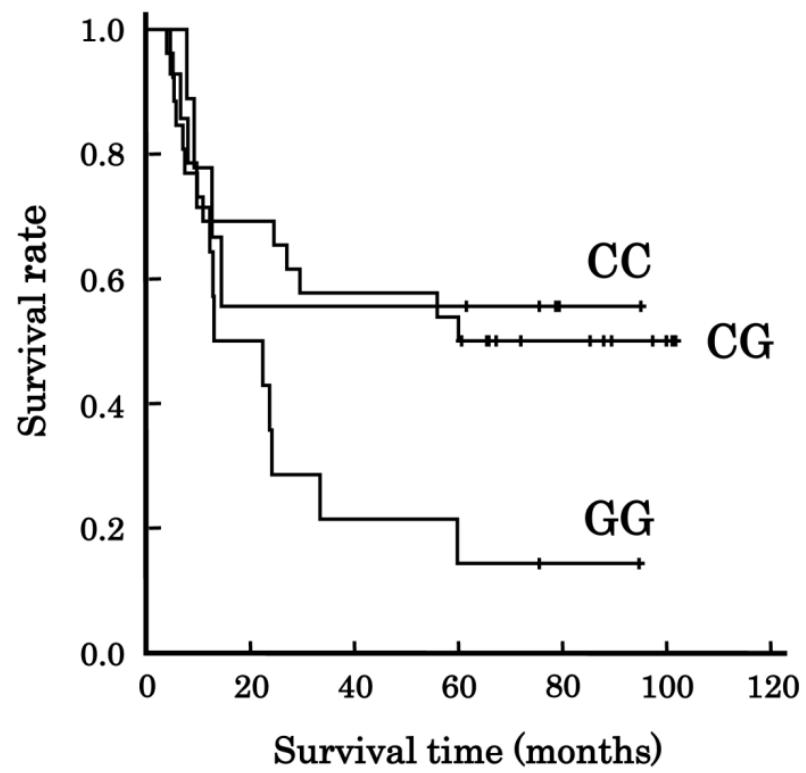

Figure I. Association of VEGF -634C/G genotype with long-term survival in Japanese patients with esophageal squamous cell carcinoma. Lines: patients with CC-634 (N=9), CG-634 ( $\mathrm{N}=26)$, and $\mathrm{GG}-634(\mathrm{~N}=14)$. The survival tended to depend on the genotype $(p=0.079$, Log-rank test).
Table 3. VEGF $-634 \mathrm{C} / \mathrm{G}$ genotype in the patients with a complete response, but survival of less than 5 years.

\begin{tabular}{llllll}
\hline & & \multicolumn{2}{c}{5 years or more } & \multicolumn{2}{c}{ Less than 5 years } \\
& & CR & non-CR & CR & non-CR \\
\hline CC & 9 & 4 & 1 & 0 & 4 \\
CG & 26 & 10 & 4 & 2 & 10 \\
GG & 14 & 2 & 0 & 5 & 7 \\
\hline
\end{tabular}

\section{Discussion}

VEGF, an endothelial cell-specific mitogen, was discovered in the 1980s [24-29], and more than 20 years of investigation has clarified that VEGF inhibits the apoptosis of endothelial cells, increases vascular permeability, and promotes angiogenesis [30-32]. VEGF is a member of a structurally related VEGF family; VEGF (VEGF-A), VEGF-B, VEGF-C, VEGF-D, and placenta growth factor (PIGF) [30-32]. VEGF and related proteins are critical for development, growth and metastasis of tumors, and their expression levels have been demonstrated to be predictive of resistance to treatment [30-32]. Genetic polymorphisms in the promoter region, 5'UTR, and 3'UTR of the VEGF gene are associated with VEGF levels in plasma or tumors, and therefore can be diagnostic, prognostic, and predictive biomarkers for patients with tumors [20-23].

In this study, it was suggested that the VEGF $-634 \mathrm{C} / \mathrm{G}$ genotype is possibly predictive of long-term survival after treatment with a definitive 5-FU/CDDP-based CRT (Table 2, Figure 1). For this protocol, the cardiopulmonary late toxicities are a matter of debate, and the incidence of mortality was reported to be $3-12 \%$ for the patients with a CR $[8,9]$. Recently, it has been suggested that the cardiopulmonary toxicities and subsequent malignancy observed in cancer survivors are presumably due to radiation and/or a certain class of anticancer drugs $[33,34]$; however, the incidence of mortality due to cardiopulmonary late toxicities was $2 \%$ or less in two large randomized trials, in which CRT alone was compared with CRT with surgical treatment $[11,12]$. Here, there were 7 patients with a CR, but survival of less than 5 years. Their VEGF -634C/G genotype was different from others, and 2 of 7 patients died from cardiopulmonary late toxicities. If we can obtain compelling evidence concerning the VEGF $-634 \mathrm{C} / \mathrm{G}$ genotype, we can optimize therapeutic treatment based on VEGF genetic profiling.

Angiogenesis plays a protective role in ischemic heart disease and myocardial infarction, and VEGF 
expression in the myocardium increases tentatively after hypoxia [30]. Acute and chronic hypoxias result in an increase in the secretion of VEGF into the lung [30]. We do not have enough data to clarify the role of VEGF in cardiopulmonary diseases, but VEGF genetic variations might be biomarkers for patients with cardiopulmonary diseases. In conclusion, VEGF -634C/G is possibly predictive of long-term survival after treatment with a definitive 5-FU/CDDP-based CRT. Further clinical studies with a larger number of cases are needed to clarify the effects of this genotype.

\section{Competing Interests}

The authors have declared that no competing interest exists.

\section{References}

1. Cooper JS, Guo MD, Herskovic A, et al. Chemoradiotherapy of locally advanced esophageal cancer: long-term follow-up of a prospective randomized trial (RTOG 85-01). Radiation Therapy Oncology Group. JAMA. 1999; 281: 1623-1627.

2. Herskovic A, Martz K, al-Sarraf M, et al. Combined chemotherapy and radiotherapy compared with radiotherapy alone in patients with cancer of the esophagus. N.Engl.J.Med. 1992; 326: 1593-1598.

3. al-Sarraf M, Martz K, Herskovic A, et al. Progress report of combined chemoradiotherapy versus radiotherapy alone in patients with esophageal cancer: an intergroup study. J.Clin.Oncol. 1997; 15: 277-284.

4. Begg C, Cho M, Eastwood S, et al. Improving the quality of reporting of randomized controlled trials. The CONSORT statement. JAMA. 1996; 276: 637-639.

5. Ohtsu A, Boku N, Muro K, et al. Definitive chemoradiotherapy for T4 and/or M1 lymph node squamous cell carcinoma of the esophagus. J.Clin.Oncol. 1999; 17: 2915-2921.

6. Kaneko K, Ito H, Konishi K, et al. Definitive chemoradiotherapy for patients with malignant stricture due to T3 or T4 squamous cell carcinoma of the oesophagus. Br.J.Cancer. 2003; 88: 18-24.

7. Tahara M, Ohtsu A, Hironaka S, et al. Clinical impact of criteria for complete response (CR) of primary site to treatment of esophageal cancer. Jpn.J.Clin.Oncol. 2005; 35: 316-323.

8. Ishikura S, Nihei K, Ohtsu A, et al. Long-term toxicity after definitive chemoradiotherapy for squamous cell carcinoma of the thoracic esophagus. J.Clin.Oncol. 2003; 21: 2697-2702.

9. Kumekawa $\mathrm{Y}, \mathrm{Kaneko} \mathrm{K}$, Ito $\mathrm{H}$, et al. Late toxicity in complete response cases after definitive chemoradiotherapy for esophageal squamous cell carcinoma. J.Gastroenterol. 2006; 41: 425-432.

10. Morota M, Gomi K, Kozuka T, et al. Late toxicity after definitive concurrent chemoradiotherapy for thoracic esophageal carcinoma. Int.J.Radiat.Oncol.Biol.Phys. 2009; 75: 122-128.

11. Stahl M, Stuschke M, Lehmann N, et al. Chemoradiation with and without surgery in patients with locally advanced squamous cell carcinoma of the esophagus. J.Clin.Oncol. 2005; 23: 2310-2317.

12. Bedenne L, Michel $\mathrm{P}$, Bouché $\mathrm{O}$, et al. Chemoradiation followed by surgery compared with chemoradiation alone in squamous cancer of the esophagus: FFCD 9102. J.Clin.Oncol. 2007; 25: 1160-1168.

13. Sakaeda T, Yamamori M, Kuwahara A, et al. Pharmacokinetics and pharmacogenomics in esophageal cancer chemoradiotherapy. Adv.Drug Deliv.Rev. 2009; 61: 388-401.

14. Miki I, Tamura T, Nakamura T, et al. Circadian variability of pharmacokinetics of 5-fluorouracil and CLOCK T3111C genetic polymorphism in patients with esophageal carcinoma. Ther.Drug Monit. 2005; 27: 369-374.

15. Okuno T, Tamura T, Yamamori M, et al. Favorable genetic polymorphisms predictive of clinical outcome of chemoradiotherapy for stage II/III esophageal squamous cell carcinoma in Japanese. Am.J.Clin.Oncol. 2007; 30: 252-257

16. Sakaeda T, Yamamori M, Kuwahara A, et al. VEGF G-1154A is predictive of severe acute toxicities during chemoradiotherapy for esophageal squamous cell carcinoma in Japanese patients. Ther.Drug Monit. 2008; 30: 497-503.

17. Kuwahara A, Yamamori M, Nishiguchi K, et al. Replacement of cisplatin with nedaplatin in a definitive 5-fluorouracil/cisplatin-based chemora- diotherapy in Japanese patients with esophageal squamous cell carcinoma. Int.J.Med.Sci. 2009; 6: 305-311.

18. Kuwahara A, Yamamori M, Nishiguchi K, et al. Effect of dose-escalation of 5-fluorouracil on circadian variability of its pharmacokinetics in Japanese patients with Stage III/IVa esophageal squamous cell carcinoma. Int.J.Med.Sci. 2010; 7: 48-54

19. Kuwahara A, Yamamori M, Fujita M, et al. TNFRSF1B A1466G genotype is predictive of clinical efficacy after treatment with a definitive 5-fluorouracil/cisplatin-based chemoradiotherapy in Japanese patients with esophageal squamous cell carcinoma. J.Exp.Clin.Cancer Res. 2010; 29: 100 .

20. Hansen TF, Jakobsen A. Clinical implications of genetic variations in the VEGF system in relation to colorectal cancer. Pharmacogenomics. 2011; 12: 1681-1693.

21. Jain L, Vargo CA, Danesi R, et al. The role of vascular endothelial growth factor SNPs as predictive and prognostic markers for major solid tumors. Mol.Cancer Ther. 2009; 8: 2496-2508.

22. Schneider BP, Radovich M, Miller KD. The role of vascular endothelial growth factor genetic variability in cancer. Clin.Cancer Res. 2009; 15: 5297-5302.

23. Cao C, Fang JJ, Ying T, et al. Vascular endothelial growth factor $+936 \mathrm{C} / \mathrm{T}$ and $+405 \mathrm{G} / \mathrm{C}$ polymorphisms and cancer risk: a meta-analysis. Arch.Med.Res. 2010; 41: 548-557.

24. Senger DR, Galli SJ, Dvorak AM, et al. Tumor cells secrete a vascular permeability factor that promotes accumulation of ascites fluid. Science. 1983; 219: 983-985.

25. Criscuolo GR, Merrill MJ, Oldfield EH. Further characterization of malignant glioma-derived vascular permeability factor. J.Neurosurg. 1988; 69: 254-262.

26. Ferrara N, Henzel WJ. Pituitary follicular cells secrete a novel heparin-binding growth factor specific for vascular endothelial cells. Biochem.Biophys.Res.Commun. 1989; 161: 851-858.

27. Connolly DT, Heuvelman DM, Nelson R, et al. Tumor vascular permeability factor stimulates endothelial cell growth and angiogenesis. J.Clin.Invest. 1989; 84: 1470-1478.

28. Leung DW, Cachianes G, Kuang WJ, et al. Vascular endothelial growth factor is a secreted angiogenic mitogen. Science. 1989; 246: 1306-1309.

29. Keck PJ, Hauser SD, Krivi G, et al. Vascular permeability factor, an endothelial cell mitogen related to PDGF. Science. 1989; 246: 1309-1312.

30. Kajdaniuk D, Marek B, Foltyn W, et al. Vascular endothelial growth factor (VEGF) - part 1: in physiology and pathophysiology. Endokrynol.Pol. 2011; 62: 444-455.

31. Kajdaniuk D, Marek B, Foltyn W, et al. Vascular endothelial growth factor (VEGF) - part 2: in endocrinology and oncology. Endokrynol.Pol. 2011; 62: 456-464.

32. Tugues S, Koch S, Gualandi L, Li X, et al. Vascular endothelial growth factors and receptors: anti-angiogenic therapy in the treatment of cancer. Mol.Aspects Med. 2011; 32: 88-111.

33. Carver JR, Shapiro CL, Ng A, et al; ASCO Cancer Survivorship Expert Panel. American Society of Clinical Oncology clinical evidence review on the ongoing care of adult cancer survivors: cardiac and pulmonary late effects. J.Clin.Oncol. 2007; 25: 3991-4008.

34. Armstrong GT, Liu Q, Yasui Y, et al. Late mortality among 5-year survivors of childhood cancer: a summary from the Childhood Cancer Survivor Study. J.Clin.Oncol. 2009; 27: 2328-2338. 